\title{
Interview with Davide Pozzi
}

\author{
By Yvonne Ng
}

Fall 2014 Issue of KINEMA

\section{INTERVIEW WITH DAVIDE POZZI, DIRECTOR, L'IMMAGINE RITROVATA}

Less often under the spotlight than filmmaking, producing or reviewing, film preservation and restoration are nevertheless crucial in keeping film cultural heritage alive for future generations. While preservation focuses on the proper storage of a film in a climate-controlled environment and may sometimes include film repair and copying, restoration aims to return a film to its entirety and original image quality as intended by its filmmakers, either through photochemical or digital processes.

In recent decades, it has become increasingly clear to filmmakers, film historians, archives and libraries around the world that there is an urgent need to preserve and restore the fast growing amount of recorded film material that is rapidly being lost to deterioration. At the same time, film studios and film archives are realizing the commercial potential of restoring their collections of classics and re-releasing them theatrically as well as for home entertainment. These factors are driving the demand for film restoration services such as those of L'Immagine Ritrovata.

L'Immagine Ritrovata (the rediscovered image) is one of the most highly regarded and comprehensive laboratories specializing in film restoration today. Under the direction of the 37-year-old Davide Pozzi it has restored seminal works such as Rome, Open City (Roma città aperta, Roberto Rossellini, Italy, 1945), Hiroshima mon amour (Hiroshima my Love, Alain Resnais, France-Japan, 1959); Manila in the Claws of Neon (Maynila sa mga Kuko ng Liwanag, Lino Brocka, Philippines, 1975) and Dragon Inn (Lóng mén kè zhàn, King Hu, Taiwan, 1967). Based in Bologna, Italy, L'Immagine Ritrovata was spawned by the film archive and research centre Cineteca di Bologna, which also organises Il Cinema Ritrovato, an annual festival with a rich programme in rediscovered and restored films. A part of L'Immagine Ritrovata's mission is educational outreach through its Film Restoration Summer School / FIAF (The International Federation of Film Archives) Summer School in Bologna as well as abroad. After attending the Restoration School Asia in Singapore at the end of 2013, the interviewer spoke to Davide Pozzi to learn more about the film laboratory and its work.

KINEMA: L'Immagine Ritrovata has a reputation as one of the best in the field of film restoration. How did it come into existence?

Davide Pozzi: L'Immagine Ritrovata was founded in 1992, after two years of training and preparation. The reason for its existence was because at that time in Italy, there was no laboratory for film restoration and the Cineteca di Bologna was not happy spending money trying to get films restored in some commercial lab somewhere, only to receive restorations that were completely unacceptable. This was the reason why the Cineteca di Bologna decided to invest in people and money to create its own lab, focusing only on restoration.

There were some key years. At the very beginning, the lab was only a photochemical lab for printing and processing pictures, because at that time, the priority was to save and preserve the film heritage. Then in 1996, the lab added the sound department and that was already a digital department. In 2005, we started a digital department for the restoration of the film image, so this was a very important date. At the end of 2007, we did the first edition of the Film Restoration School.

How did you become involved with film restoration work and with L'Immagine Ritrovata? I went to Bologna when I was 19 years old to study. As you know, the University of Bologna is the oldest in the West. For most of the people who are now working with me in the lab - there are eighty-two of us it's the same story. We came here to study and then we stayed to work. I went to Bologna to study film history at the university and in my second year, there was a very small course in film restoration taught by Gian Luca Farinelli who is now the director of the Cineteca di Bologna and I was completely fascinated by the subject.

Then during my third year in university, I went to Paris on the Erasmus student exchange programme. I 
was lucky because I was able to go to the Cinémathèque française where I became a cinephile. When I came back to Bologna, I decided it would be the dream of my life to work here. I was quite lucky because I was selected for the Archimedia European Training Network for the Promotion of Cinema Heritage. It was a project created by the European Union. The training was divided into five steps. We studied one week in Paris, another in London, Belgium, Lisbon and Amsterdam and it was very useful to know the network of film archives and film labs. At the end of this course, the Cineteca di Bologna called me to ask if I was interested to work for them because at the time, they were moving their safety vaults to a new place. So I started to work in 2001 for the Cineteca di Bologna and in 2003, I was moved to L'Immagine Ritrovata. I became the director of the L'Immagine Ritrovata in 2006.

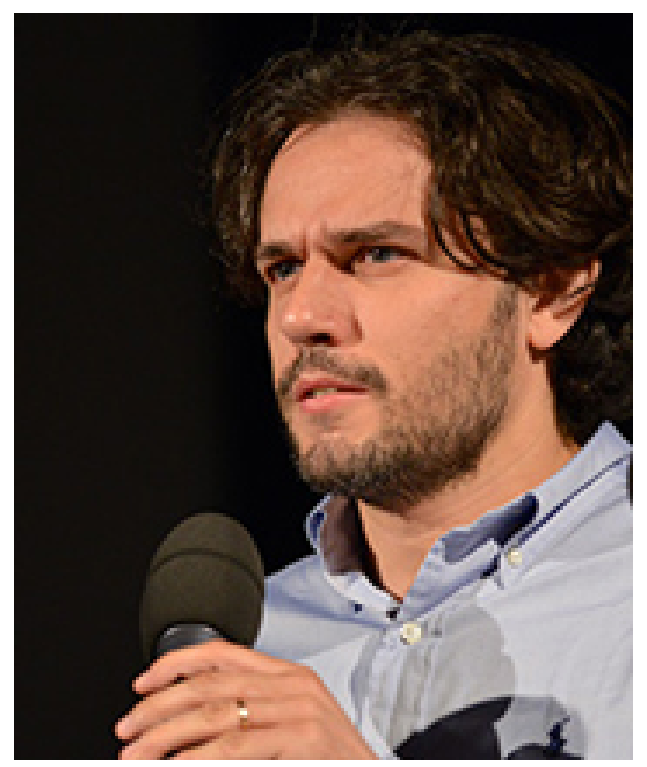

Figure 1: Davide Pozzi

How long on average does it take to restore a film?

Usually between four to nine months, but it really depends on the condition of the film. If a film is recent and is in good shape, we can do the restoration even in two months. If a film is in very bad shape and will take a long time to repair and process, it can take more than one year to restore.

Where are the films coming from mostly, nowadays?

At the very beginning, the clients were only the film archives. Now it's changed a bit because we not only have film archives but also some private film libraries, such as Pathé or Studio Canal from Europe and Sony, Warner Bros. or Fox from the US. In Asia, we have clients like Emperor Motion Pictures and so on. There is a third category, which is the Foundation, such as the World Cinema Project of the Film Foundation chaired by Martin Scorsese or the Technicolor Foundation. Generally speaking, we have three kinds of clients - film archives, film libraries and Foundations.

\section{What kind of restoration requirements do your clients have? Are they very different?}

They are different because a film can be restored in several ways and there are different methodologies. It really depends. You may have a client who prefers a more respectful restoration. Someone else may prefer a more aggressive restoration. It really depends on the title, on the client, on the film. This is a very delicate point because you can restore a film in many, many ways. One of our tasks is to try to guide the clients in what we think is the best and more correct way.

Has there been an occasion when what you believed should be done was in conflict with your client's wishes? How do you handle such a situation?

Yes, sometimes I'm in a situation when I would like to restore a film in a certain way but the client wants to 
do it in another way. In that case, I try to explain my reasons and maybe add some tests to show the client why it might be better to follow my way. But at the end, the final word is the client's.

When I disagree with a client, I always try, first of all, to better understand the client's reasons for doing the restoration; secondly, to better explain my reasons for doing it in a particular way. And I have to say that almost always, at the end of the day, we agree on what to do. In the time I've been here, there have been very, very few cases when we were in complete disagreement.

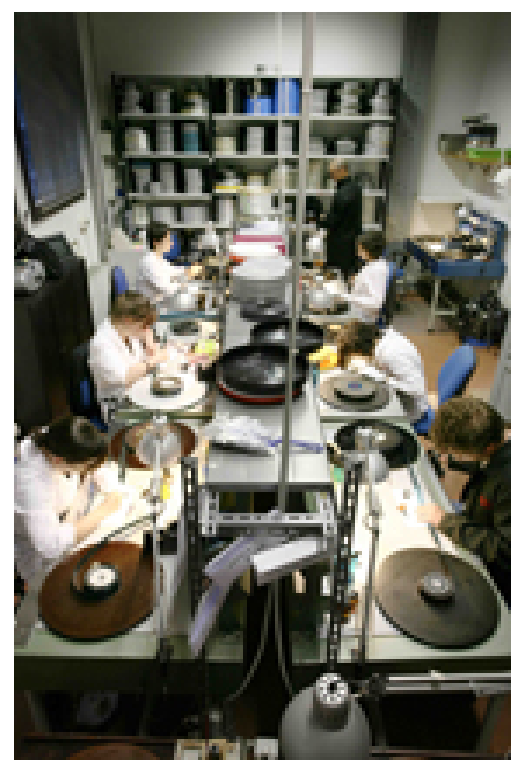

Figure 2: Film repair

\section{So the clients usually take your advice in the end?}

Yes. The reason why people come to do their restoration in Bologna is because they trust our experience. I think one of our tasks is to explain to our clients and other people the way we do restoration and to share our experience. The reason why we do the summer film restoration school is because we are more than happy to share our experience, to share what we think about restoration, how we like to do our restoration. If you take time to explain and to discuss with the clients, at the end, you'll agree on what to do. You'll always find a solution but it takes time. I think part of our mission is not only to restore and deliver but also to try to build the right concept of restoration.

\section{What are the main challenges of digital restoration?}

More than 90 percent of restoration we do today is digital. The big challenge is how to do a good restoration, how to do a respectful restoration using digital tools because with the digital tools today, you can do almost everything, even too much. For me, the key point is to respect the original look of the film. For a film made during the photochemical age, for instance, grain is one of the big questions of digital restoration. Respecting the original grain of the film means not to use any degrain or to add noise.

And another thing, even more important to me, is to respect the original colour grading of the film. With digital tools, we can restore a film, let's say, from the 1960s, and make a very new colour correction with the modern eye, which is fake for me. We have to respect the original look of the film. This means we have to take the time to find a vintage print and screen it and see how it was with the colour correction. We should also to try to find the DOP [director of photography] or the director if they are still alive and consult them. It's very important, because with the tools we have today, it's easy to over-restore. This is valid not only for the colour correction but also for the sound. If we have to restore a film from the $30 \mathrm{~s}$, then we have to respect the sound from the $30 \mathrm{~s}$, which is, of course, completely different from that of today.

By the way, although most of the restoration work we do is digital, we still work quite a lot with the 
photochemical workflow but only for preservation. Preservation is very important, even more important than restoration because restoration can be done only if preservation has been done before.

By preservation, I mean, for instance, when we have an original camera negative, we have to print photochemically to get an interpositive. Also, the best way to save or preserve a restoration is to do a film-out. It means your data files come back on a new $35 \mathrm{~mm}$ internegative for long-term preservation.

\section{And the main challenges of photochemical restoration?}

The photochemical process is a stable technology. The main challenge is to try to optimize it and also to be able to work with it because there is almost only one celluloid film stock in existence now and that is Kodak. The challenge is not technological but has to do with experience because today, it is very difficult to train people using film stock. There are very few photochemical labs left in the world. In our processing department, we use a lot of black-and- white film stock but we are one of the very few labs in the world working with black-and-white films.

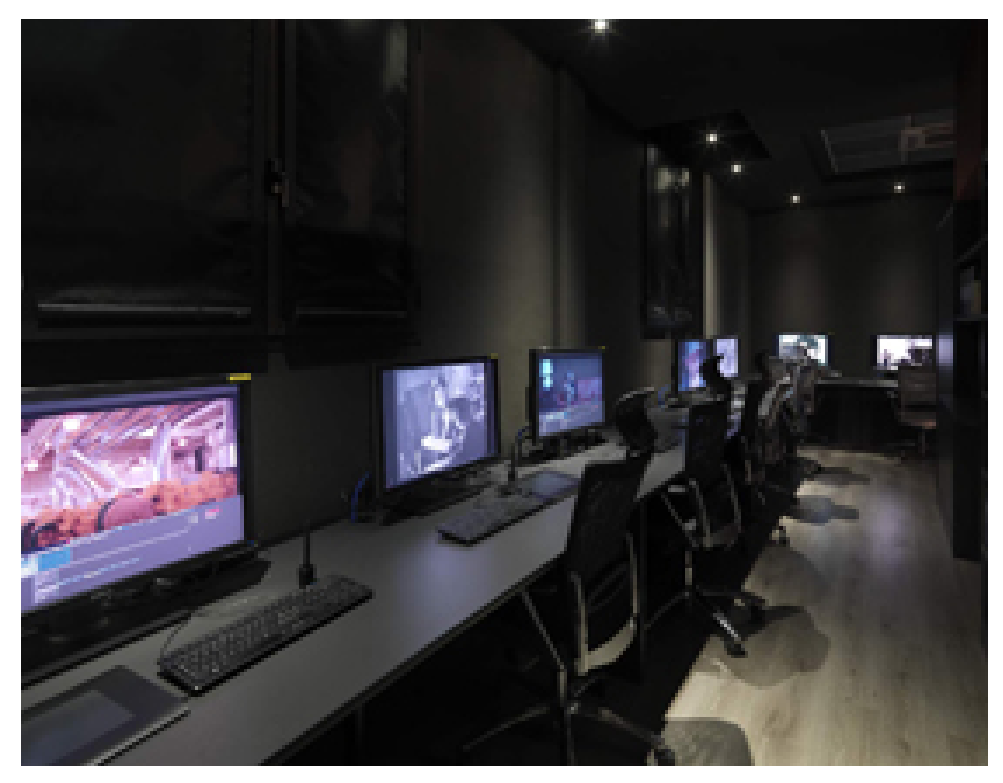

Figure 3: Digital cleaning

\section{What is the basic workflow of restoring a film?}

The workflow is very simple but as always, the simple things are the most difficult to execute. The workflow starts with collecting every element possible of the film title to be restored. This is because we want to compare them and we want to be sure that everything is in the right place. We have to compare everything in order to avoid finding some older material two years after the restoration and to be able to come back to our restoration if necessary.

So first of all, we have to check the film. If the perforations are broken, we have to repair them. Then we have to compare the elements and after that we start the digitalization, using the film scan to digitize up to $2 \mathrm{~K}$ or $4 \mathrm{~K}$. Then we start the long step of digital cleaning. After that, we have to do the colour correction. At the same time that we are restoring the picture, we restore the sound. For the sound, we have to repair the best sound elements which are, most of the time, optical tracks or when we have a film with magnetic tracks, then we have to digitize the sound and restore it. At the very end, picture and sound come together again and we are able to create the DCP [Digital Cinema Package] to record HD masters or to make a new film-out for long-term preservation. Very generally speaking, this is the workflow.

What is the most important part of the workflow for you?

For me, before you start a restoration, you have to spend time and effort to study and to compare everything to be sure how the restoration should be carried out. For instance, we need to make a $4 \mathrm{~K}$ wet scan to make 
a test. We take the element, we make a $2 \mathrm{~K}$ test, $4 \mathrm{~K}$ test, dry test, wet test and we compare the best element with the second-best element - for example, an OCN [original camera negative] with an IP [interpositive]. We look at the grain and we evaluate. In addition, we make a simulation using only 2000-3000 frames and we restore this completely. Only then can we know, even before starting, the final quality of the restoration.

The most important thing is that the client knows in advance the final quality of the restoration. It is very important to be on the same level. This is for me a key factor in every restoration. We receive the elements, we spend time to study them, to compare them, to make a test. We show the test to the client and if the client accepts it, is happy with it, and if we agree on the final quality of the restoration, we go ahead.

This is very important because when we are talking about heritage films, old films, they are not always in good condition nor do we always have the original camera negative for restoration. For example, sometimes we have a very poor $16 \mathrm{~mm}$ print or a very poor and scratched release print. It is important to show the client what the final quality of the restoration will be. As well, there are always some budget issues and it is important to evaluate everything. A restoration could be very expensive and it could make sense if we have a film title that is top-of-the-line quality but sometimes there's no reason to spend more money. Then maybe we have to find another solution or some good compromise in terms of quality and budget. It's always needed. My goal is not only to restore in the best way but also to have the client give me a second title to restore.

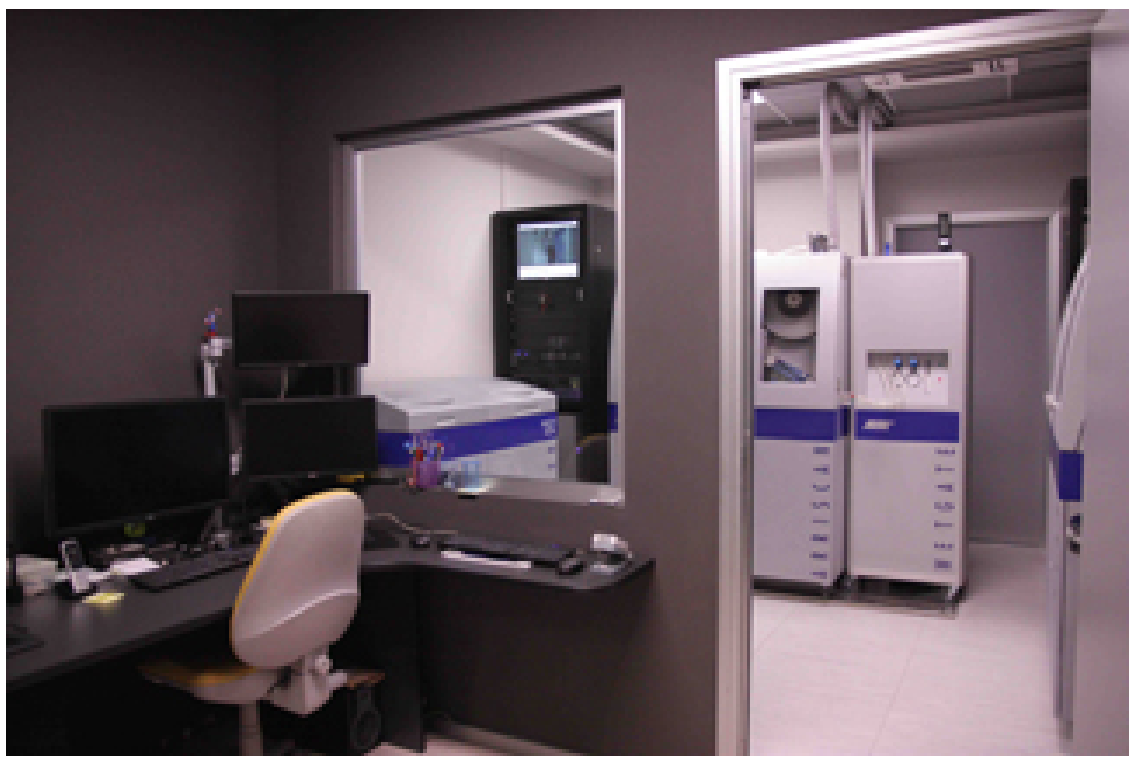

Figure 4: ARRI scanner

\section{Could you tell us something about the restoration of The Cabinet of Dr. Caligari which premiered at the $64^{\text {th }}$ International Film Festival in Berlin this year?}

The Cabinet of Dr. Caligari was one of the most important restorations we've ever done. The film was restored by the Friedrich Wilhelm Murnau Stiftung (and curated by Anke Wilkening), which is the rights holder in Germany and they found the original camera negative from 1919. The original camera negative was missing reel number one. The restoration, which was done in $4 \mathrm{~K}$, used the original camera negative from reel numbers two, three, four, five and six. For reel number one, we used the best surviving print. We collected prints from Bologna, New York, Paris, London as well as Montevideo and many from Germany. We collected everything, compared and studied them and decided on the best element for the restoration. The camera negative was a little bit incomplete but we were able to complete everything using the best surviving print. We were also able to restore the original German intertitles because we found the original German intertitles on a $16 \mathrm{~mm}$ print that we used as a reference for editing and as a source for the restoration of the German intertitles. In finding the prints, we were also able to reconstruct all the original tinting and 
toning, because as you know, the film was not in black-and-white but in monochrome colour. It was a long restoration. It took almost two years, from April 2012 to January 2014. The restored film premiered in February 2014.

Were you surprised by anything while you were doing the restoration?

I was surprised by the quality of the original camera negative. When I was a young student, I saw this film on a very bad videotape and now it's like seeing another film.

\section{Is there anything you would like to share about other restorations you did?}

In the past we restored a collection of Lumière brothers' films. That was one of our biggest challenges because the films had only one circle perforation per frame instead of four, which meant they were impossible to scan. We got in touch with ARRI and they developed a sprocketless transport system and so we were able to digitize the films. It was one of the most amazing restorations we ever did, to be honest. Last year, we restored Hiroshima mon amour. Every film is a new story, a new problem, a new challenge. This is the reason why our job is always so fascinating because it's never the same.

The last question is about the training and education through the Film Restoration / FIAF Summer School. I was very glad and fortunate to be a participant of the Film Restoration School Asia held in Singapore in November 2013. Could you comment more on this aspect of the L'Immagine Ritrovata's work?

As I mentioned before, we are very happy to share our experience. There are no secrets to our work. If we find a solution to fix a problem, we are more than happy to share with others because don't forget, our "mother" is the Cineteca di Bologna and it's in our spirit to be ready to teach and to train people. We love to share our experience, we love to meet people and to share problems. This was the reason why the first Film Restoration / FIAF Summer School was born in 2007. We did five editions in Bologna and then last year, we decided to take up the huge challenge of organizing the next edition of this school abroad, which we finally did in Singapore.

Why Singapore? Because Zhang Wenjie, [who headed the National Museum of Singapore's Cinémathèque, and is now festival director of the Singapore International Film Festival] went in 2009 to attend the summer school in Bologna. He was very enthusiastic about the school and said it had changed his life. So we kept in touch and discussed to meet again. At the beginning, as a joke, we said, "Let's organise a school in Singapore." And step by step, we did!

It was a big challenge but I must say it was also quite a big success. It was an incredible experience for us, before all. I think it was also quite appreciated. In July 2014, we hosted the sixth summer school (the longer edition) in Bologna. The next edition is scheduled in July 2016 together with the FIAF Congress that will take place in Bologna. For the next year - 2015 - we have already received some proposals to organise the same school abroad that we did in Singapore, which was very satisfying for me. [The Film Preservation and Restoration School India will take place in Mumbai from 22-28 February 2015, hosted by the Film Heritage Foundation in collaboration with The Film Foundation's World Cinema Project, Fondazione Cineteca di Bologna and L'Immagine Ritrovata.]

I think the participants who were at the school would say the same. It was truly an enriching and a wonderful experience.

Thank you very much, it works both ways! You know, when we talk to the archivists and the people attending the school, we can learn from your experience, your problems, and it's always a two-way exchange. It's always a growing experience.

\section{References}

[Picture credits: All pictures, L'Immagine Ritrovata.] 


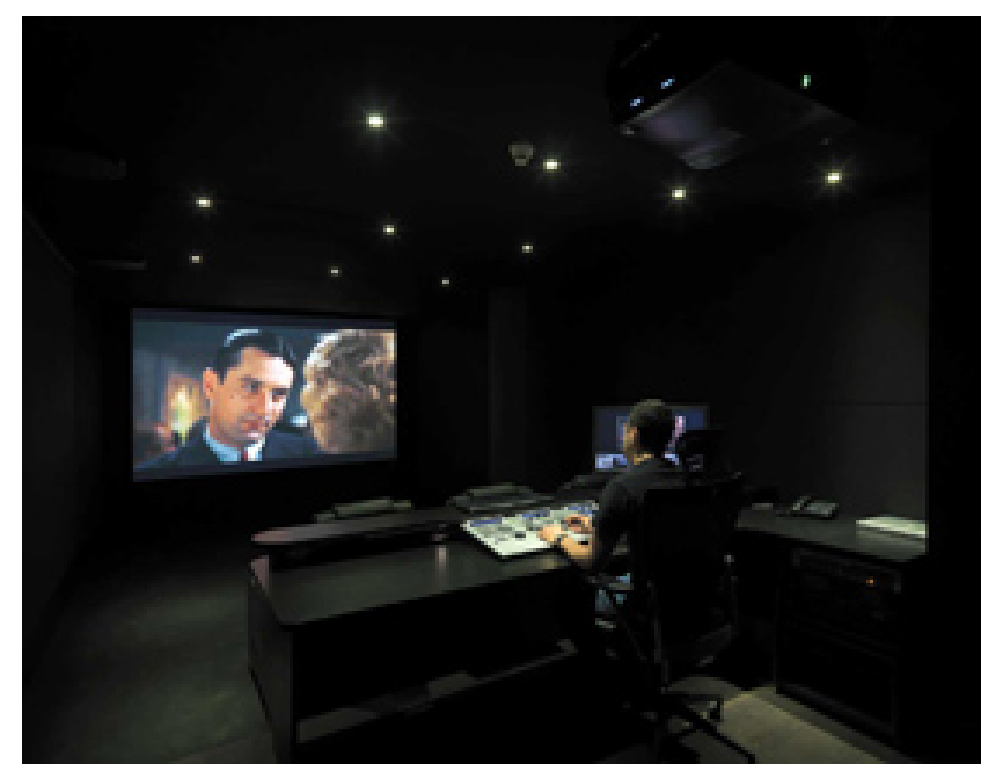

Figure 5: Colour correction

\section{Author Information}

Yvonne NG is the co-author of Latent Images: Film in Singapore Second edition (NUS Press, 2010); Latent Images: Film in Singapore (OUP, 2000) and Latent Images: Film in Singapore CD-ROM (Singapore, 2003). She has written on Singapore and Asian cinema and contributes to the International Film Guide. 